\title{
Pharmacological approaches to habituation of the acoustic startle response in rats
}

\author{
DAVID H. OVERSTREET \\ School of Biological Sciences, The Flinders University of South Australia \\ Bedford Park, South Australia 5042
}

\begin{abstract}
In a series of six experiments, the effects of pharmacological manipulations of the cholinergic (DFP, physostigmine, atropine, pilocarpine), the noradrenergic and dopaminergic (damphetamine), and the serotonergic (p-chlorophenylalanine and p-chloroamphetamine) systems on habituation of the acoustic startle response in rats (to a $1000-\mathrm{Hz}, 110-\mathrm{dB}$ tone) were examined. Only acute administration of DFP was found to significantly reduce the rate of habituation. There was a tendency of physostigmine and pilocarpine to depress the startle response and for atropine to facilitate it, suggesting that the cholinergic system may modulate the startle response level. Manipulations of the noradrenergic, dopaminergic, and serotonergic systems did not alter either the startle response level or the rate of habituation. However, recent literature from other laboratories was reviewed, and it was concluded that the doses and/or other conditions used in the present experiments were not appropriate for observing significant changes in the startle response. It was further concluded that either the neurotransmitter systems examined in the present study were not involved in the processes underlying habituation or that the pharmacological manipulations used were not appropriate for differentiating among the mechanisms that may underlie habituation.
\end{abstract}

Habituation is a relatively transient form of behavioral plasticity which has been demonstrated to occur in most members of the animal kingdom (see Peeke \& Herz, 1973). Until recently, the main approaches to the study of this phenomenon have been electrophysiological and behavioral (e.g., Horn \& Hinde, 1970; Peeke \& Herz, 1973). However, a number of investigators have begun to use pharmacological approaches to the study of habituation (e.g., Davis \& Sheard, 1974b; Davis, Svensson, \& Aghajanian, 1975; Fechter, 1974; Warburton \& Groves, 1969; Williams, Hamilton, \& Carlton, 1974). One rationale behind these approaches is the feeling that an elucidation of the transmitter system(s) that is (are) involved in habituation would permit the design of experiments which could distinguish between two or more of the postulated neuronal mechanisms underlying habituation (see Groves \& Thompson, 1970). In the present paper, a series of drugs which have relatively specific effects on the cholinergic, noradrenergic, dopaminergic, and serotonergic systems were utilized to determine if one of these neurochemical systems may specifically

These studies were carried out in the Department of Psychobiology, University of California, Irvine, while the author was supported by a PHS predoctoral fellowship, No. 48981. This research was partially supported by Grant MH 18788 from NIMH to Roger W. Russell. The author would like to express his thanks to Richard F. Thompson and Roger W. Russell for their encouragement and to Frank W. Dalglish for his expert technical assistance. mediate habituation of the acoustic startle response in rats.

\section{EXPERIMENT 1}

The first experiment was designed to examine relationships between two superficially similar phenomena: habituation, the reduction in response to a repeated stimulus, and tolerance, the reduction in effect to repeated administration of a drug. Recent reviews of these two phenomena suggest that comparable mechanisms may underlie them: e.g., a reduction in the release of neurotransmitters or a reduction in the sensitivity of postsynaptic receptors for the neurotransmitters (Groves \& Thompson, 1970; Kalant, Leblanc, \& Gibbins, 1971; Russell, Overstreet, Cotman, Carson, Churchill, Dalglish, \& Vasquez, 1975). It was reasoned, therefore, that a study of the two processes in parallel might give further information about the similarity in mechanisms that might underlie them.

\footnotetext{
Method

A pilot study involving six male Sprague-Dawley rats indicated that the pattern of habituation was approximately the same if the intersession interval was $72 \mathrm{~h}$. This result suggested that designs which used the rat as its own control would be appropriate for exploring the effects of drugs or habituation of the acoustic startle response.

For this and subsequent studies, the parameters for the startle stimulus were a $1,000-\mathrm{Hz}$ tone of approximately $110 \mathrm{~dB}$ and $1 \mathrm{sec}$ duration. The rat was enclosed in a small restraining cage which was attached to a postage stamp scale. This whole assembly was enclosed in a large sound-attenuated chamber. A strain gauge
} 
was used to record the startle response, which was measured in millimeter deflection of a polygraph pen from baseline.

Three days before the start of the habituation session, each animal was placed in the apparatus for initial testing. Following a 10-min warm-up, three tones, $90 \mathrm{sec}$ apart, were presented. The average of these three tones was taken as the animal's baseline startle response. Diisopropyl fluorophosphate (DFP), an irreversible anticholinesterase agent which depresses many behaviors upon acute administration (Russell, Vasquez, Overstreet, \& Dalglish, 1971; Russell, Warburton, \& Segal, 1969), was injected intramuscularly in a dose of $1.0 \mathrm{mg} / \mathrm{kg}$ into the experimental animals $(\mathrm{N}=8) 24 \mathrm{~h}$ before their habituation session. The control animals $(\mathrm{N}=8)$ received $1.0 \mathrm{mg} / \mathrm{kg}$ doses of the arachis oil vehicle $24 \mathrm{~h}$ before their first habituation session. Subsequent doses of DFP or arachis oil were $0.5 \mathrm{mg} / \mathrm{kg}$ and were given at 3-day intervals. The habituation sessions also occurred at 3-day intervals, so that each injection of DFP or arachis oil preceded the habituation session by $24 \mathrm{~h}$. There were five sessions, each consisting of 42 presentations of the $1,000-\mathrm{Hz}, 110-\mathrm{dB}$ tone at 30-sec intervals. The duration of the tone was $1 \mathrm{sec}$.

For each animal, the performance during the habituation session was averaged over blocks of three trials and expressed as a percentage of the baseline determined 3 days earlier. Medians were used to indicate the performance of the whole group, and appropriate nonparametric statistics (Siegel, 1956) were used to assess the significance of various changes and drug effects, with the 0.05 level of confidence being chosen as the significance level. Mann-Whitney U tests or Kruskal-Wallis tests were used to assess intergroup differences, and Friedman one-way analyses of variance tests were used to assess intragroup differences.

\section{Results and Discussion}

The results of the first two administrations are presented in Figure 1A. In this and subsequent figures, the data were obtained by averaging each sequence of three responses and expressing this as a percentage of the baseline startle response. The only obvious trend in Figure $1 \mathrm{~A}$ is that the experimental rats showed less habituation following the first injection of DFP than did the control rats. Significant differences (Mann-Whitney U tests) were observed between the groups after the first injection on Blocks 2, 4, and 14. It is important to note that, despite these intergroup differences, a significant decline in response during the session was apparent in all groups. These declines were confirmed to be significant trends with the use of Friedman tests (Siegel, 1956).

The two groups showed comparable rates of decline after each of the subsequent injections of DFP or arachis oil, as is reflected in Figures $1 \mathrm{~B}$ and 1C. There were no significant differences between groups for any block of trials. Conversely, each group showed a significant decline in response throughout the session, which was confirmed by Friedman tests.

Thus, the experimental animals showed less habituation following the first injection of DFP than did the control animals, but thereafter the groups were comparable in their rates of habituation. One interpretation of these results is that raised acetylcholine $(\mathrm{ACh})$ levels due to the cholinesterase (ChE) inhibition produced by DFP may impair habituation, but that once tolerance has developed to these high $\mathrm{ACh}$ levels, habituation proceeds normally. One might predict, therefore, that injections of a reversible inhibitor of $\mathrm{ChE}$ would also impair habituation. The following study examines the hypothesis.

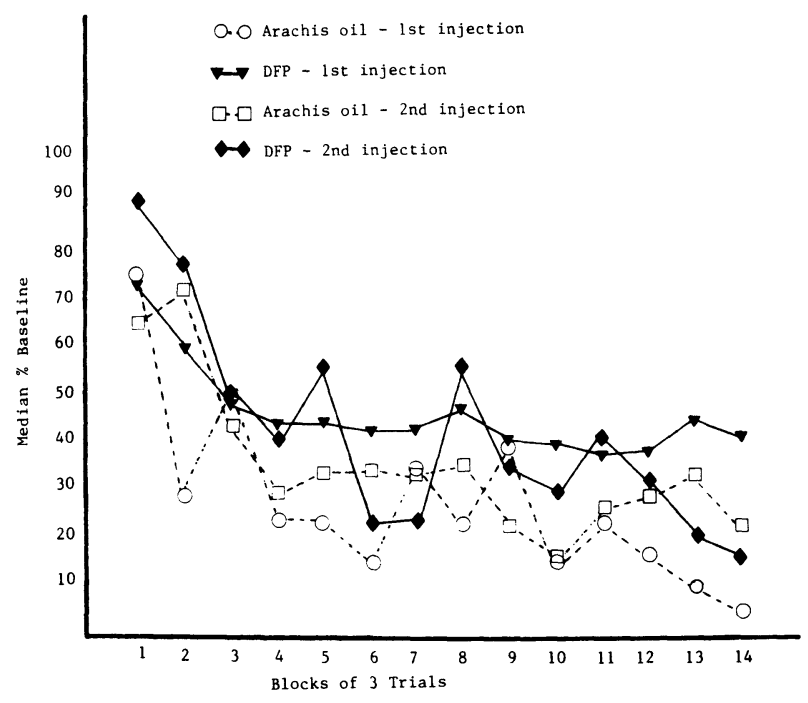

Figure 1A. Habituation of the acoustic startle response following one or two injections of DFP or arachis oil. The first injection was a $1-\mathrm{mg} / \mathrm{kg}$ dose of each agent $24 \mathrm{~h}$ prior to the habituation session; the second, a $0.5-\mathrm{mg} / \mathrm{kg}$ dose $24 \mathrm{~h}$ prior to the habituation session, which occurred 3 days after the first. Each point is the median for eight rats.

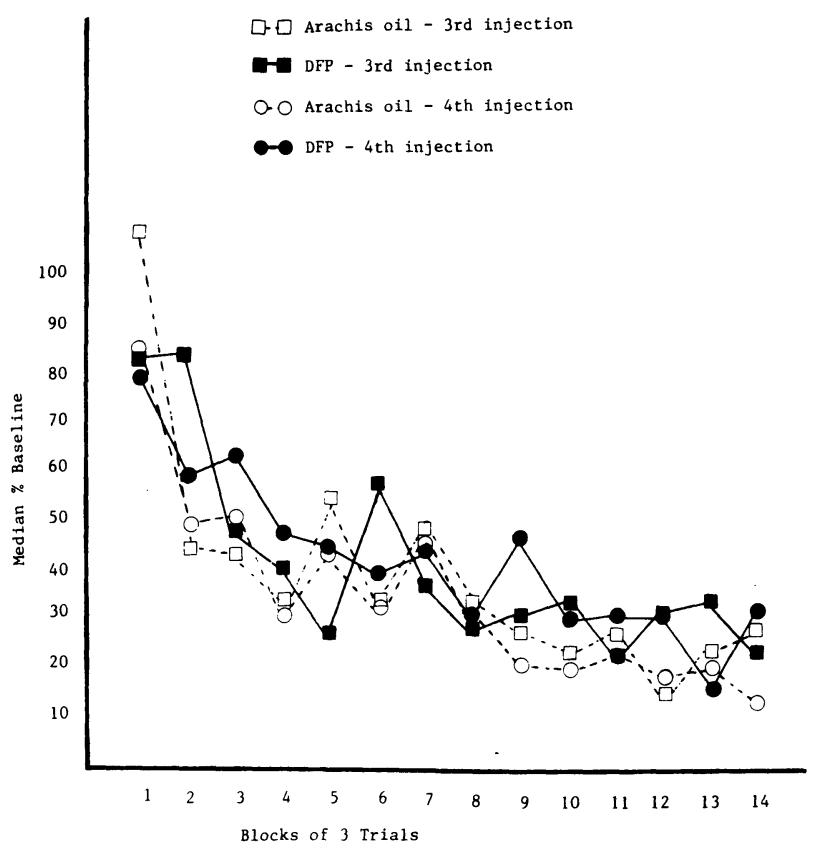

Figure 1B. Habituation of the acoustic startle response following three or four injections of DFP or arachis oil. The $0.5-\mathrm{mg} / \mathrm{kg}$ injections were given $24 \mathrm{~h}$ prior to the third and fourth habituation sessions, respectively. Each point is the median for eight rats. 


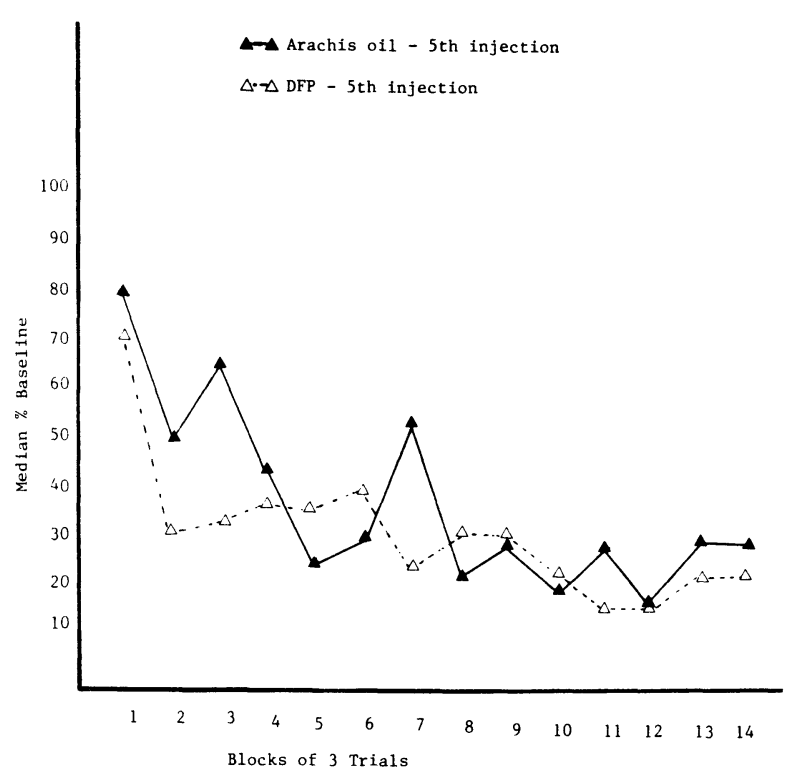

Figure 1C. Habituation of the acoustic startle response following five injections of DFP or arachis oil. The $0.5-\mathrm{mg} / \mathrm{kg}$ injections were given $24 \mathrm{~h}$ prior to the fifth habituation session. Each point is the median for eight rats.

\section{EXPERIMENT 2}

Physostigmine, a reversible inhibitor of $\mathrm{ChE}$ (Koelle, 1970), has been used extensively to investigate the role of the cholinergic system in various behavioral phenomena (e.g., Russell, 1966, 1969). Typically, the effects of this drug are compared with those of neostigmine, a quaternary reversible anticholinesterase agent, to determine whether the effects of anticholinesterase treatment can be ascribed to the central or peripheral actions of the drugs. In the present study, neostigmine was not used because physostigmine did not significantly alter the rate of habituation.

\section{Method}

The animals, as in the previous and future experiments, were naive male Sprague-Dawley rats, approximately 90 days old and weighing $400-450 \mathrm{~g}$ at the beginning of the experiment. An independent groups design was used for this drug. There were four groups of four animals each: The control group received isotonic saline immediately before the 10 -min warm-up period preceding the habituation session; the experimental groups received $0.1,0.2$, or $0.4 \mathrm{mg} / \mathrm{kg}$ physostigmine salicylate (as the salt), respectively, immediately before the 10-min warm-up period. The study was run in two replications so that the total $\mathrm{N}$ for each group was eight. As in the previous study, the startle response baseline of each animal was determined by the presentation of three $1,000-\mathrm{Hz}$, 110 -dB tones $90 \mathrm{sec}$ apart, while the habituation sessions consisted of 42 presentations of the tone at 30 -sec intervals.

\section{Results and Discussion}

The results are summarized in Figure 2. A marked sensitization of the startle response was observed for the first block of three trials in the groups receiving saline and $0.1 \mathrm{mg} / \mathrm{kg}$ physostigmine. This was not seen in the groups receiving the two higher doses of the drugs, but no significant differences were observed for any block of trials using the KruskalWallis test (Siegel, 1956). In contrast, analyses with the Friedman test confirmed that all groups showed a significant decline in response over trials. Thus, there was no evidence in this experiment that physostigmine altered the rate of habituation of the acoustic startle response.

\section{EXPERIMENT 3}

Carlton $(1963,1968,1969)$ has on several occasions suggested that the cholinergic system may mediate habituation and has based his evidence upon studies using cholinolytic drugs, e.g., atropine and scopolamine. However, most of the behavioral situations examined by Carlton do not meet the conditions for studying habituation directly. Warburton and Groves (1969) found that scopolamine raised the basic response level of acoustic startle, but did not alter the rate of habituation, thus failing to support Carlton's model. The present study was designed to gather additional information of the effects of cholinolytics on habituation of an acoustic startle response by examining the effects of atropine.

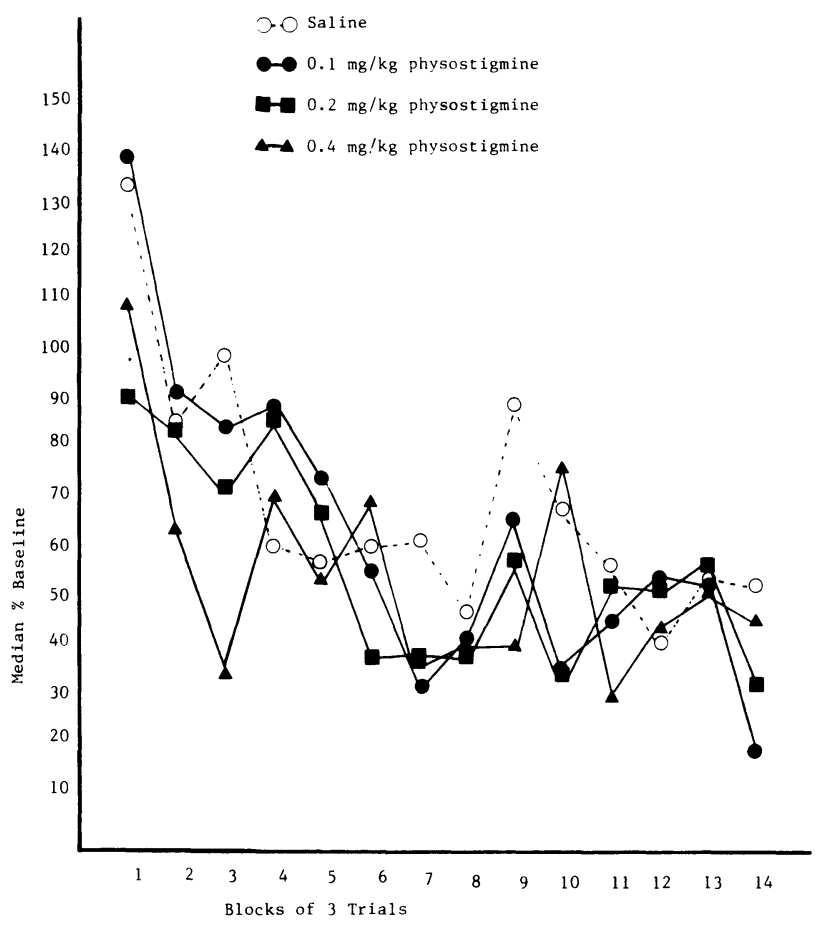

Figure 2. Habituation of the acoustic startle response following different doses of physostigmine. The drug was administered as the salicylate salt (IP) immediately prior to the 10 -min warm-up that preceded the habituation session. Each of the four groups contained eight separate animals. 


\section{Method}

The design was the same as that for physostigmine reported above: four groups of four animals each, with two replications. The control group received IP injections of isotonic saline, while the three experimental groups received $1.0,5.0$, or $10.0 \mathrm{mg} / \mathrm{kg}$ IP injections of atropine sulfate (as the salt) $20 \mathrm{~min}$ before the 10 -min warm-up period.

\section{Results and Discussion}

Figure 3 summarizes the results. It appeared that atropine markedly increased the startle response on the first Block of three trials; however, there was considerable variability within groups and a KruskalWallis test did not reveal any significant differences between the groups. Similar nonsignificant differences were found at each of the other blocks. Conversely, Friedman analyses confirmed that each group showed a significant decline in response over trials.

These results would appear to support the earlier findings of Warburton and Groves (1969). There is certainly a trend for the atropine-treated animals to show higher responses during the session, but habituation still develops. There is clearly no support for the hypothesis that the cholinergic system mediates habituation of the acoustic startle response in rats.

The independent groups design used in the present experiment appeared to cloud interpretations of the results because of large individual differences within groups. This was also the case for physostigmine, when there were fairly large but nonsignificant differences between the control group and those groups receiving the two higher doses of physostigmine (see Figure 2). To overcome this problem, future experiments utilized a repeated measures design whenever possible.

\section{EXPERIMENT 4}

The previous results with cholinergic drugs suggest that the cholinergic system may modulate the acoustic startle response itself but does not play any obvious rule in habituation of this response. These findings permit two predictions about the effects of pilocarpine, which acts directly upon muscarinic receptors to mimic the action of $\mathrm{ACh}$, on the acoustic startle response: (1) It should produce a reduction in the startle amplitude; and (2) it should not alter the rate of habituation of the startle response.

\footnotetext{
Method

The basic design for this study was a 4 by 4 Latin square, with the treatments being given at 3-day intervals. The four treatments were isotonic saline or $1.0,5.0$ or $10.0 \mathrm{mg} / \mathrm{kg}$ pilocarpine hydrochloride (as the salt). The IP injections were given immediately before the 10-min warm-up period. There were two replications of this basic design, giving a total of eight rats for each treatment. As in the previous experiments, each animal's startle response baseline was determined by averaging its response to three presentations of the $1,000-\mathrm{Hz}, 110-\mathrm{dB}$ tone given $90 \mathrm{sec}$ apart.
}

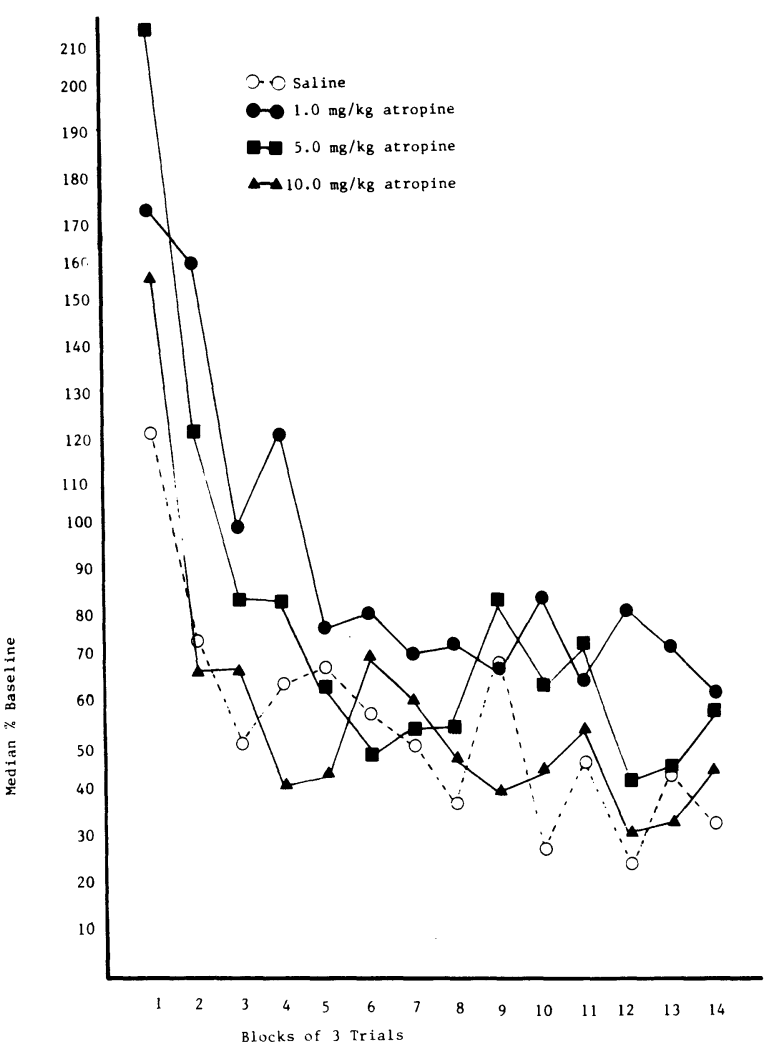

Figure 3. Habituation of the acoustic startle response following different doses of atropine. The drug was administered as the sulfate salt (IP) 20 min prior to the 10 -min warm-up that preceded the habituation session. Each of the four groups contained eight separate animals.

\section{Results and Discussion}

These results, summarized in Figure 4, correspond almost perfectly with the predictions made above. The startle response was markedly reduced in all of the pilocarpine-treated animals. Significant differences among treatments, analyzed by the Friedman test, were observed for the 1st, 2nd, 6th, and 10th blocks. In fact, the response was reduced so much after the two higher doses of pilocarpine that no significant trend for a decrease in response over trials could be found for these treatments. There was a significant decrease over trials for the saline and the $1.0-\mathrm{mg} / \mathrm{kg}$ pilocarpine treatments. Thus, habituation was observed in pilocarpine-treated animals as long as the dose was not high enough to reduce the initial startle response to a very low level.

In sum, cholinergic drugs affect the basic startle response level: Those drugs raising the levels of $\mathrm{ACh}$ or mimicking its action lower the response level, while those which block the muscarinic action of $\mathrm{ACh}$ raise the response level. However, none of the drugs, with the possible exception of DFP, altered the rate of habituation of the response. These findings suggest that the cholinergic system has little or 


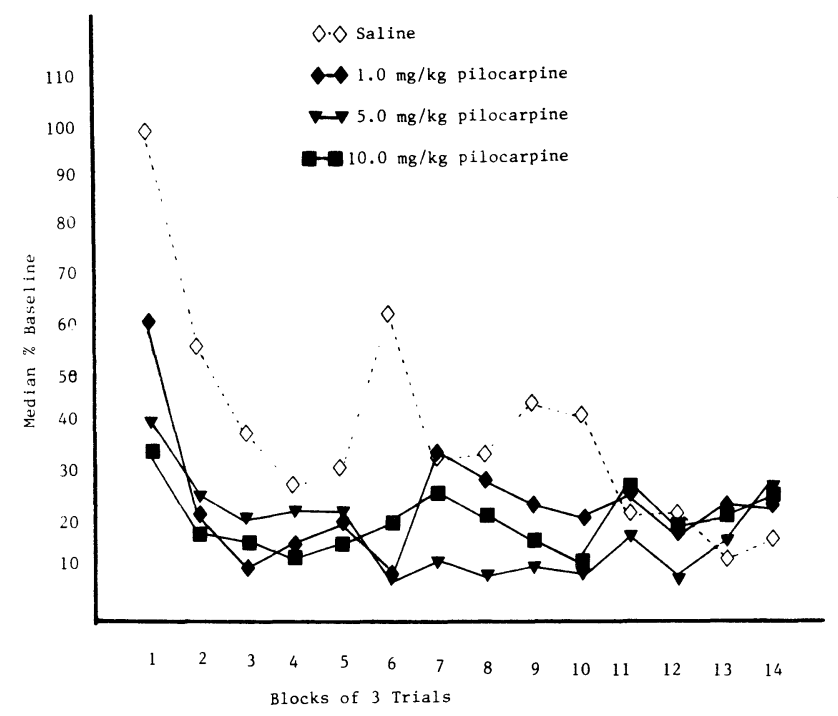

Figure 4. Habituation of the acoustic startle response following different doses of pilocarpine. The drug was administered as the hydrochloride salt (IP) immediately prior to the 10 -min warm-up that preceded the habituation session. Each treatment was based on eight animals, which were tested under each of the treatments by means of a Latin square design.

no role in habituation of the acoustic startle response.

\section{EXPERIMENT 5}

It appeared that other neurotransmitter systems were more likely candidates as mediators of habituations than the cholinergic system. To assess the potential role of the noradrenergic and/or dopaminergic systems in this process, the following experiment observed the effects of d-amphetamine, which promotes the release of both noradrenaline and dopamine (e.g., Carr \& Moore, 1972; Von Voightlander \& Moore, 1973).

\section{Method}

A 4 by 4 Latin square design in two replications was used. The four treatments were isotonic saline and $0.5,1.0$, and 2.0 doses of d-amphetamine sulfate (as the salt). The IP injections were given $20 \mathrm{~min}$ before the 10 -min warm-up period. The remainder of the procedures were the same as for the previous experiments.

\section{Results and Discussion}

As can be seen in Figure 5, all the treatments resulted in comparable rates of habituation, each being confirmed as significant by the Friedman test. In addition, tests of dose-response effects revealed mainly nonsignificant differences between the treatments, the only exception being the significantly higher response for the $0.5-\mathrm{mg} / \mathrm{kg}$ dose for the third block. Thus, d-amphetamine, in the doses used in this experiment, had little or no influence on the initial startle response amplitude or on habituation of the startle response. More work with other adrenergic agents must be completed before we can adequately evaluate the role of the noradrenergic system in the process of habituation.

\section{EXPERIMENT 6}

While the earlier studies were being carried out, there appeared a couple of papers suggesting the lowered levels of serotonin might retard the rate of habituation of an acoustic startle response or induce the reappearance of a previously habituated startle response (Conner, Stolk, Barchas, \& Levine, 1970; Stolk, Barchas, \& Conner, 1970). The final experiment in this series was an attempt to replicate and extend these findings by examining the effects of p-chlorophenylalanine (PCPA) and p-chloroamphetamine (PCA), two drugs which lower the levels of brain serotonin by inhibiting tryptophan hydroxylase, the rate-limiting enzyme in serotonin biosynthesis (Koe \& Weismann, 1966; Miller, Cox, Snodgrass, \& Maickel, 1970).

\section{Method}

Because PCA and PCPA have relatively long-lasting effects, it was not possible to use a repeated measures design, as was used for amphetamine and pilocarpine. There were three groups of eight rats each, housed in groups of four as in previous experiments. The control group received saline, one experimental group received $300 \mathrm{mg} / \mathrm{kg}$ of PCPA and the other group, $3.5 \mathrm{mg} / \mathrm{kg}$ of PCA. These injections were given IP immediately after the baseline sessions, or approximately 3 days before the habitua-

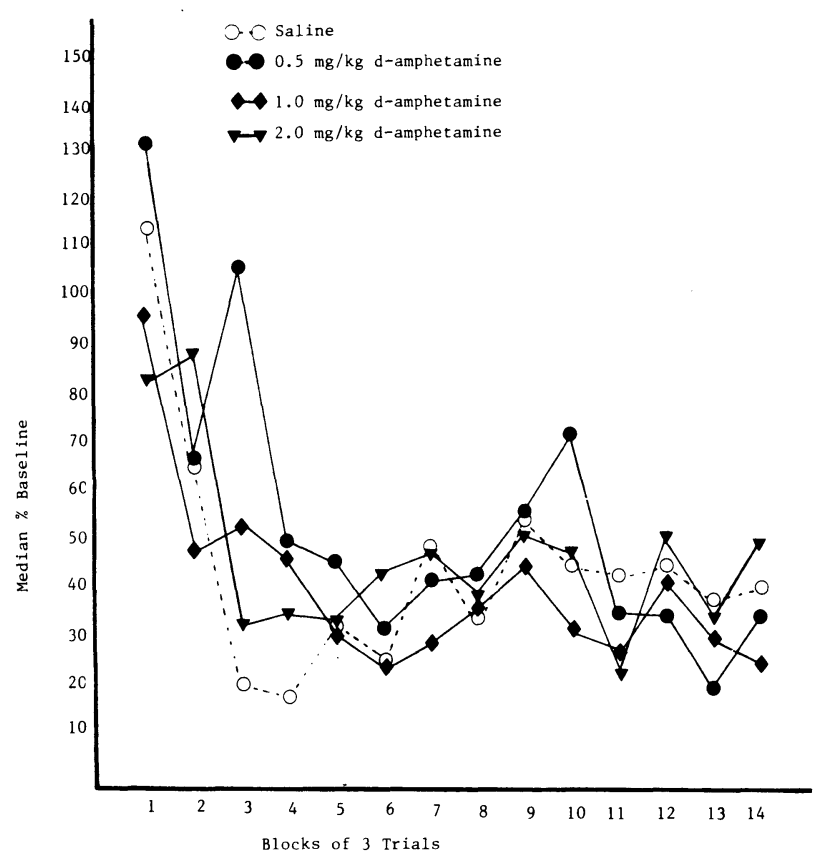

Figure 5. Habituation of the acoustic startle response following different doses of d-amphetamine. The drug was administered as the sulfate salt (IP) 20 min prior to the 10 -min warm-up that preceded the habituation session. Each treatment was based on eight rats, which were tested under each of the treatments by means of a Latin square design. 
tion sessions to insure a low level of brain serotonin at the time of the behavioral measurements (Koe \& Weisman, 1966; Miller et al., 1970).

\section{Results and Discussion}

Figure 6 illustrates the results. As with the previous experiments in which independent groups were used, large variabilities within groups were observed. There were no significant differences among the three groups, except for the last block, when the control group was significantly higher than the other two groups. All treatments resulted in a significant decline in startle response over trials. Thus, intrasession habituation can still occur in rats with low levels of serotonin.

However, the outcome of this study may have been affected by the housing of the animals. It has been reported that PCPA-treated animals appear to be hyper-reactive to environmental stimuli, including pain (Brody, 1970; Tenen, 1967). Thus, group housing led to a significant amount of fighting among the experimental animals, and all animals treated with PCA and PCPA were observed to have a number of wounds about the hind legs. This fighting could have influenced the results on the startle response. Therefore, several replications of the PCPA study were attempted with the rats being housed singly. All of these studies were essentially negative. PCPA did not significantly alter the rate of habituation during the session. Neither did it produce a reappearance of the startle response which had been previously habituated, in contrast to the findings of previous workers (Conner et al., 1970). On the whole, then, it would appear that intrasession habituation can still develop even though an animal has radically lowered brain levels of serotonin. The effects of serotonin depletion on intersession habituation are unclear as yet.

\section{GENERAL DISCUSSION}

In brief, the present studies suggest that (1) the cholinergic system may modulate the startle response level, (2) the noradrenergic, dopaminergic, and serotonergic systems appear to have little influence on the startle response, (3) habituation of the startle response may occur even when these neurotransmitter systems have been pharmacologically manipulated. However, a number of recent studies indicate that the above conclusions, particularly the second, should be regarded with caution. These studies will now be reviewed systematically and integrated with the findings of the present studies.

\section{ACh}

Bignami (1976) has recently reviewed extensively and incisively the literature on the behavioral effects of central cholinergic drugs. He points out that the

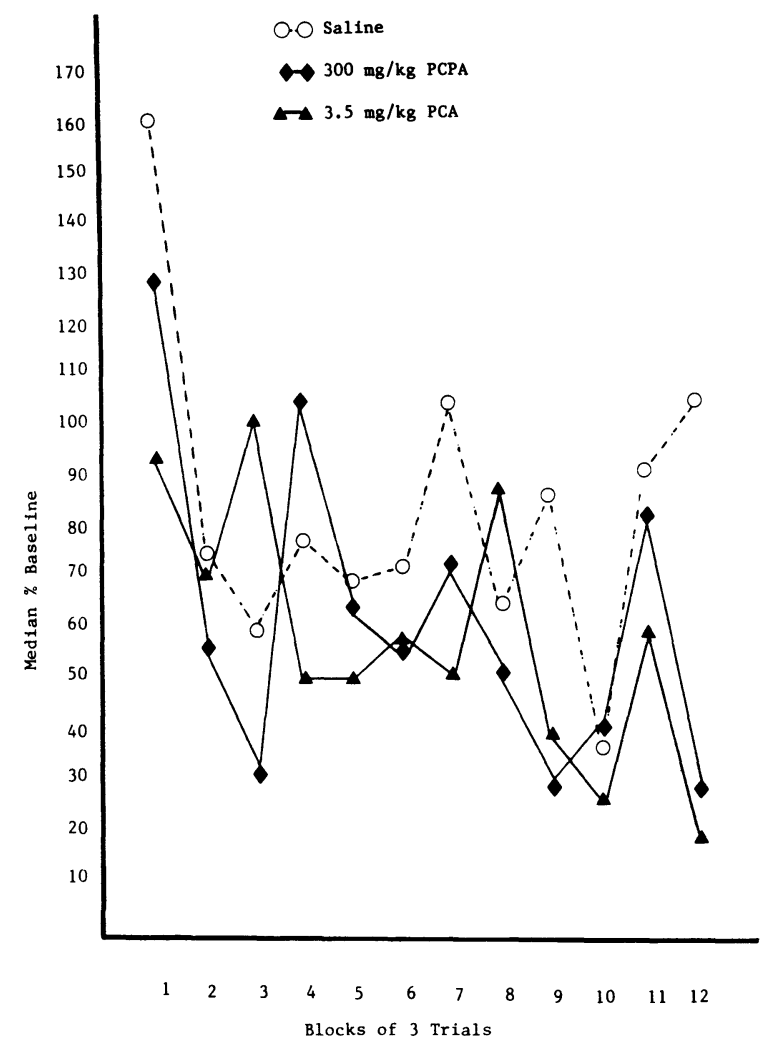

Figure 6. Habituation of the acoustic startle response following isotonic saline, p-chlorophenylalanine (PCPA) or p-chloramphetamine (PCA). The drugs were administered as the methyl ester hydrochloride (PCPA) or sulfate (PCA) salts (IP) 3 days prior to the habituation session. Each of the three groups contained eight separate rats.

effects of these drugs are complex and the results obtained in any given experiment may be dependent on a number of variables. It is fairly conclusive, however, that antimuscarinic drugs do not interfere with habituation of the acoustic startle response, since there is agreement between several independent studies (Payne \& Anderson, 1967; Warburton \& Groves, 1969; Williams et al., 1974). The study by Williams et al. (1974) was a particularly interesting one inasmuch as scopolamine, an antimuscarinic drug similar to atropine, was found to interfere with habituation of exploratory behavior, but not with habituation of a startle response. However, even more recent studies by Stewart and Blain (1975) have questioned these results, as scopolamine did not interfere with the rate of habituation of ambulation and rearing responses in an open field. We (Foster $\&$ Overstreet, unpublished results) have observed that rats also habituate to an open field following treatment with atropine. Stewart (1976) has recently reported that physostigmine also did not alter the rate of habituation of ambulation, rearing, and grooming of rats in an open field. Thus, the bulk of the recent literature is consistent with the findings present in 
these experiments: Drugs which mimic $\mathrm{ACh}$ or raise its levels decrease responding, while those which block the muscarinic receptors for $\mathrm{ACh}$ increase responding; however, neither of these manipulations significantly alters the rate of habituation.

\section{NA and DA}

The results of the experiments with amphetamine were confirmed and significantly extended in a number of recent studies by Davis and his co-workers (Davis \& Aghajanian, 1976; Davis et al., 1975). The interesting finding was that low doses of $d$ amphetamine, comparable to those used in the present studies, did not influence the startle response, while doses of $3-4 \mathrm{mg} / \mathrm{kg}$ or higher resulted in a facilitation of the startle response (Davis et al., 1975). That these results suggested that stimulation of the dopaminergic system facilitated the acoustic startle response was confirmed by the more recent finding that apomorphine, a specific DA receptor stimulant, enhanced the startle response in very low $(0.19 \mathrm{mg} / \mathrm{kg})$ doses (Davis \& Aghajanian, 1976). These latter studies also sufficiently accounted for the lack of effects of apomorphine on the startle response reported previously (Fechter, 1974): This agent has a biphasic effect on the response, an early facilitatory phase, lasting about $40 \mathrm{~min}$, and a later depressant phase; Fechter (1974) tested his animals for a brief period $40 \mathrm{~min}$ after administration of apomorphine.

The lack of significant effects of d-amphetamine in the present experiments may be related to the possibility that at the doses used the noradrenergic and dopaminergic systems were equally stimulated (see Davis \& Aghajanian, 1976, for a fuller development of this argument), particularly since clonidine, a directly acting noradrenergic alpha receptor stimulant, has been reported to depress the startle response (Fechter, 1974). Further work with additional pharmacological agents will be necessary to confirm this interesting hypothesis that the noradrenergic and dopaminergic systems are opposing systems in the modulation of the acoustic startle response.

Unfortunately, as elegant as the recent studies from the Davis laboratory are, they tell us little about the role of these two catecholamines in habituation of the startle response. The main reason for this is that they have developed a procedure which produces a relatively stable startle response in the control animals, permitting a time-dependent assessment of the potentiation and depression of the response without a contamination of response decrement. The effects of apomorphine, clonidine, and higher doses of d-amphetamine on the acoustic startle response under the paradigm reported in the present studies must be carried out before any conclusions can be made about the role of NA and DA in habituation.

\section{Serotonin}

Recent studies from Davis and co-workers have also provided some confirmatory evidence for the lack of significant results by PCPA and PCA reported in the present experiments. For example, Davis and Sheard (1976) reported that PCA inhibited startle amplitude 15 min after injection, facilitated it 2-15 h after, and did not influence initial startle amplitude $24 \mathrm{~h}, 1$ week, and 4 weeks after. Since the startle response was examined $72 \mathrm{~h}$ after PCA in the present study, the finding of no significant alteration of the startle response is consistent with the above results. The other important observation by Davis and Sheard (1976) was that, even in situations where PCA facilitated the startle response, the rate of habituation was not altered. The present results are again consistent with these findings.

The findings of earlier work by Davis and Sheard (1974b) are also relevant here. LSD was found to facilitate the startle response in rats in a manner comparable to that reported for rats with lesions in the serotonin-containing cells in the raphe nuclei (Davis \& Sheard, 1974a). The argument was advanced that the serotonergic system may mediate a sensitization system which may modulate the startle response: activation of this system would depress startle and blocking this system would facilitate startle under appropriate experimental conditions (Davis \& Sheard, 1974b). Facilitation of startle may not have been observed in the present studies because the animals may have been tested too long after the serotonin-depletion was achieved by administering PCA and PCPA (refer to Davis \& Sheard, 1976, for a fuller development of this argument).

\section{Conclusions}

Returning now to the suggestions made earlier, the first remains essentially unchanged: the cholinergic system mudulates the basal startle response level, with activation of the system depressing and blockade of it facilitating startle. The second conclusion must be substantially modified in light of the evidence presented above: activation of the dopaminergic system facilitates startle (Davis \& Aghajanian, 1976), while activation of the noradrenergic and serotonergic systems appears to depress startle (Fechter, 1974) or modulate its sensitization (Davis \& Sheard, 1974b, 1976). Furthermore, it has been suggested that the dopaminergic system is directly involved in the startle response, while the serotonergic system is only indirectly involved (Davis \& Aghajanian, 1976; Davis et al., 1975). Thus, there is some comparability in the effects of drugs on startle with their effects on behavioral arousal as 
reflected in locomotor activity (e.g., Fibiger, Lynch, \& Cooper, 1971; Fibiger, Lytle, \& Campbell, 1970; Mabry \& Campbell, 1973). However, Davis and Aghajanian (1976) have postulated that separate dopaminergic pathways may be involved in startle and locomotor activity.

The third and perhaps the most important conclusion in the present context also remains unchanged: Despite a large number of experiments involving pharmacological manipulations of four of the major neurotransmitter systems, habituation has still developed in the overwhelming majority of cases. These negative findings have therefore not permitted any elucidation of the mechanisms underlying habituation. At least two reasons for these results can be suggested. The first and simplest hypothesis is that neither ACh, NA, DA, nor serotonin is the transmitter involved in the processes underlying habituation. The second hypothesis is that pharmacological manipulations, at least those used in the past, are not appropriate for differentiating among the mechanisms underlying habituation. For example, while amphetamine may promote the release of DA or NA, thereby altering the basal startle response level, it may not be capable of affecting the decreased release of these transmitters or the reduced sensitivity of the postsynaptic receptors, two of the possible mechanisms underlying habituation. One potential approach may be to compare the rate of habituation in normal animals with that in animals which have had receptor sensitivity altered by chronic treatment with specific drugs (e.g., Baudry, Matres, \& Schwartz, 1976). It is hoped that the failure to alter habituation which has been extensively documented in the present paper will stimulate further research into the mechanisms underlying this phenomenon.

\section{REFERENCES}

Baudry, M., Martres, M. P., \& Schwartz, J. C. Modulation in the sensitivity of noradrenergic receptors in the CNS studied by the responsiveness of the cyclic AMP system. Brain Research, 1976, 116. 111-124.

Bignami. G. Nonassociative explanations of behavioural changes induced by central cholinergic drugs. Acta Neurobiologiae Experimentalis, 1976, 36, 5-90.

BRODY, J. F., JR. Behavioral effects of serotonin depletion and of p-chlorophenylalanine (a serotonin depletor) in rats. Psychopharmacologia, 1970, 17, 14-33.

Carlton, P. L. Cholinergic mechanisms in control of behavior by the brain. Psychological Review, 1963, 70, 19-39.

Carlton. P. L. Brain-acetylcholine and habituation. Progress in Brain Research, 1968, 28, 48-60.

Carlton, P. L. Brain-acetylcholine and inhibition. In J. Tapp (Ed.), Reinforcement: Current research and theories. New York: Academic Press, 1969.

CARR, L. A., \& Moore, K. E. Norepinephrine: Release from brain by d-amphetamine. British Journal of Pharmacology, 1972, 45, 96-102.

Conner, R. L., Stolk, J. M., Barchas, J. D., \& Levine, S. PCPA and habituation to repetitive auditory startle stimuli in rats. Physiology and Behaviour, 1970, 5, 1215-1219.
Davis, M., \& Aghajanian, G. K. Effects of apomorphine and haloperidol on the acoustic startle response in rats. Psychopharmacology, 1976, 47, 217-223.

Davis, M., \& ShEaRd, M. H. Habituation and sensitization of the rat startle response: Effects of raphe lesions. Physiology and Behavior, 1974, 12, 425-431. (a)

Davis, M., \& ShEARD, M. H. Effects of lysergic acid diethylamide (LSD) on habituation and sensitization of the acoustic startle response in the rat. Pharmacology, Biochemistry, and Behavior, 1974, 2. 675-683. (b)

Davis, M., \& SheARD, M. H. p-Chloroamphetamine (PCA): Acute and chronic effects on habituation and sensitization of the acoustic startle response in rats. European Journal of Pharmacology, 1976, 35, 261-273.

Davis, M., Svensson, T. H., \& Aghajanian, G. K. Effects of $d$ and $l$-amphetamine on habituation and sensitization of the acoustic startle response in rats. Psychopharmacologia, 1975, 43, 1-11.

Fechter, L. D. The effects of 1-dopa, clonidine and apomorphine on the acoustic startle reaction in rats. Psychopharmacologia, 1974, 39, 331-344.

Fibiger, H. C., LYNCH, G. S., \& COOPER, H. A biphasic action of central cholinergic stimulation on behavioral arousal in the rat. Psychopharmacologia, 1971, 20, 366-382.

Fibiger, H. C., Lytle, L. D., \& Campbell, B. A. Cholinergic modulation of adrenergic arousal in the developing rat. Journal of Comparative and Physiological Psychology, 1970, 72, 384-389.

Groves, P. M., \& Thompson, R. F. Habituation: A dual-process theory. Psychological Review, 1970, 77, 419-450.

HoRN, G., \& HINDE, R. A. Short-term changes in neural activity and behaviour. London: Cambridge University Press, 1970.

Kalant, H., Leblanc, A. E., \& Gibbins, R. J. Tolerance to, and dependence on, some non-opiate psychotropic drugs. Pharmacological Reviews, 1971, 23, 135-191.

Koe, B. K., \& Weismann, A. p-Chlorophenylalanine, a specific depletor of brain serotonin. Journal of Pharmacology and Experimental Therapeutics, 1966, 154, 499-516.

Koelle, G. B. Anticholinesterase agents. In L. S. Goodman \& A. Gilman (Eds.), The pharmacological basis of therapeutics. New York: Macmillan, 1970.

Mabry, P. D., \& Campbell, B. A. Serotonergic inhibition of catecholamine-induced behavioral arousal. Brain Research, 1973, 49, 381-391.

Miller, F. P., Cox, R. H., SNodgrass, W. R., \& Maickel, R. P. Comparative effects of p-chlorophenylalanine, p-chloroamphetamine and $\mathrm{p}$-chloro- $\mathrm{N}$ methyl-amphetamine on rat brain norepinephrine, serotonin and 5-hydroxyindole-3-acetic acid. Biochemical Pharmacology, 1970, 19, 435-442.

PAyne, R., \& Anderson, D. C. Scopolamine-produced changes in activity and in the startle response: Implications for behavioral activation. Psychopharmacologia, 1967, 12, 83-90.

Peeke, H. U. S., \& Herz, M. J. Habituation. New York: Academic Press, 1973.

Russell, R. W. Biochemical substrates of behavior. In R. W. Russell (Ed.), Frontiers of physiological psychology. New York: Academic Press, 1966.

Russell, R. W. Behavioral aspects of cholinergic transmission. Federation Proceedings, 1969, 28, 121-131.

Russell, R. W., Vasquez, B. J., Overstreet, D. H., \& Dalglish, F. W. Consummatory behavior during tolerance to and following withdrawal from chronic depression of cholinesterase activity. Physiology and Behavior, 1971, 7, 523-528.

Russell, R. W., Warburton, D. M., \& SEgal, D. S. Behavioral tolerance during chronic changes in the cholinergic. system. Communications in Behavioral Biology, 1969, 4, 121-129.

Russell, R. W., Overstreet, D. H., Cotman, C. W., Carson, V. G., Churchill, L., Dalglish, F. W., \& Vasquez, B. J. Experimental tests of hypotheses about neurochemical mechanisms underlying behavioral tolerance to the anticholinesterase. diisopropyl fluorophosphate. Journal of Pharmacology and Experimental Therapeutics, 1975, 192. 73-85. 
SIEGEL, S. Nonparametric statistics for the behavioral sciences. New York: McGraw-Hill, 1956.

STEWART, W. J. Habituation should be measured directly: Effects of physostigmine on activity. Psychological Reports, in press.

STEW ART, W. J., \& Blain, S. Dose-response effects of scopolamine on activity in the open field. Psychopharmacologia, 1975, 44, 291-295.

Stolk, J. M., Barchas, J. D., \& Conner, R. L. Relationship between brain serotonin and habituation to an auditory startle stimulus in the rat. Proceedings of American Psychological Association, 1970, 78, 827-828.

TENEN, S. The effects of p-cholorophenylalanine, a serotonin depletor, on avoidance acquisition, pain sensitivity, and related behavior in the rat. Psychopharmacologia, 1967, 9, 204-219.
Von Voightlander, P. F., \& Moore, K. E. Involvement of nigro-striatal neurons in the in vivo release of dopamine by amphetamine, amantadine and tyramine. Journal of Pharmacology and Experimental Therapeutics, 1973, 184, 542-552.

W ARB URTon, D. M..\& Groves, P. M. The effects of scopolamine on habituation of acoustic startle in rats. Communications in Behavioral Biology, 1969, 3, 289-293.

Williams, I. M., Hamilton, L. W., \& Carlton, P. L. Pharmacological and anatomical dissociation of two types of habituation. Journal of Comparative Physiological Psychology, 1974, 87, 724-732.

(Received for publication January 7, 1977; accepted February 3, 1977.) 